son is heir to the chieftainship, and voluntary retainers attach themselves to him, thus forming the nucleus of a royal regiment. Mr. Goodwin gave details of the generation-regiments of the AmaMpondo, and showed how such details might be used as evidence for dating battles, since native historians carefully remember the names of the regiments present at battles. The Rev. W. A. Norton has attempted to date the regiments of the Ba Suto, but as yet nothing of this sort has been done for the south-eastern Bantu. Mr. Goodwin's paper also interested ethnologists, since it forms another link binding the eastern Bantu into a whole, the generational regimental system being well known everywhere farther north.

\section{Action of Cinchona Alkaloids in Malaria.*}

A LTHOUGH three centuries have elapsed since A cinchona bark was introduced into European medicine for the treatment of malaria and it is nearly a century since the last of the four alkaloids-quinine, quinidine, cinchonine, and cinchonidine-which form the active constituents of the bark was discovered, there are still numerous problems to be settled in connexion with the use of the bark and its constituents in malaria. Until recently, chemotherapeutical work in this disease has been hampered by the fact that the relative values of drugs could only be investigated by extensive clinical trials in malarial countries. Much work of this kind has been done in India and Malaya by MacGilchrist, Acton, Fletcher, Sinton, and other British experts in tropical medicine, mainly to ascertain whether the present policy of concentrating on quinine as the only valuable cinchona alkaloid for the treatment of malaria is sound. Work of this kind is expensive and difficult, and final conclusions have not yet been reached.

Birds share with man susceptibility to malaria, and in recent years a method has been worked out of using them for testing new anti-malarial drugs. Facilities for such tests having been provided in Great Britain by the Chemotherapeutical Committee of the Medical Research Council, Dr. Henry, in association with Mr. J. A. Goodson, has been able to have the four cinchona alkaloids referred to above, together with a large number of their chemical derivatives, tested by Dr. Macfie in bird malaria. The results of this preliminary work support the conclusions arrived at from clinical trials that quinine and quinidine are more efficient than cinchonine, but the value of cinchonidine is still uncertain. Of the derivatives of quinine tried, the most promising is hydroquinine, which in these preliminary tests gave better results than any other drug examined. On oxidation, quinine is converted into an acid, quitenine, which is inactive in malaria, but it has been shown that activity is regained when the acid is esterified, and that in a series of such esters activity is slowly increased as the series is ascended, until at butyl and amyl esters the preparations begin to be curative instead of merely retarding the development of the malarial parasite.

In various tropical parts of the British Empire other drugs than cinchona enjoy local reputations as cures for malaria; for example, Alstonia bark in West Africa, the Far East, the Pacific Islands, and sub-tropical Australia, akuamma throughout Africa, and greenheart bark in British Guiana. All these also contain alkaloids, which have been tried in the course of this work, but the Alstonia alkaloids alone have shown any activity in bird malaria.

* Substance of a paper read by Dr. T. A. Henry before Section B (Chemistry) of the British Association at Bristol on Sept. 18.

\section{University and Educational Intelligence.}

CAmbridge.--Sir James Jeans will deliver the Rede lecture at 5.30 P.M. on Nov. 4, taking as his subject "The Mysterious Universe";.

The Appointments Committee of the Faculty of Engineering has appointed R. H. Angus, of Sidney Sussex College, to be University demonstrator in engineering.

The Appointments Committee of the Faculty of Physics and Chemistry gives notice that the Humphrey Owen Jones lectureship in physical chemistry is vacant owing to the appointment of Dr. E. K. Rideal to be professor of colloidal physics. Intending candidates for the Lectureship should send their names to the chairman of the Faculty Board of Physics and Chemistry, the Master of Pembroke College, not later than Nov. 12.

The Managers of the Balfour Fund, with the approval of the Faculty Board of Biology 'A', have made a grant of $£ 150$ from the fund to $L$. C. Beadle, of Pembroke College, for research on the biology of the East African Lakes.

Eninburgh.--Sir James Barrie was installed as Chancellor of the University on Oct. 25 and conferred honorary degrees on Sir Thomas Holland, Principal of the University, and Sir J. J. Thomson, Master of Trinity College, Cambridge, among others.

LoNDon.-The title of emeritus professor of electrical engineering in the University has been conferred on Prof. Ernest Wilson, on his retirement from the University chair of electrical engineering at King's College.

Tre Council of the Institution of Naval Architects has awarded the Yarrow Scholarship in Marine Engineering (1930) to Mr. W. J. Reynolds, of Messrs. Alexander Hall and Co., Aberdeen. The Scholarship is of the value of $£ 100$ per annum and will be held at the University of Glasgow for four years.

"The day of science is here in commerce as in industry." "These words sum up the purport of Sir Francis Goodenough's paper read before section L (Education) of the British Association at Bristol on the subject of "Education for Business." No greater service could be rendered by the Association at this time than to promote the general recognition of the truth that scientific methods are imperatively de. manded alike in the fields of production, management, and marketing. Scientific research is needed not only into methods of manufacture, handling and transport and methods of management, but also into methods of selling and the possibilities and requirements of the world's markets. In technical education for production there has been a great advance in the past twenty years, but education for marketing has not kept pace. Commerce has not hitherto been recognised as a science, and this vitally important business has been regarded too much as something people can "pick up' as they go along. In the highly competitive and increasingly scientific world of to-day, it is essential that British commerce should find recruits endowed with "character plus brains raised to the highest power by education". There must be a general recognition of these facts and a determination on the part of all concerned to raise high the standards of efficiency and probity in the conduct of British commerce, to the benefit of all engaged in it and to the credit of the nation as a whole. So will be dissipated the still surviving prejudices which have for generations imposed a social handicap on those who follow a ' commercial' career and operate despite the congestion existing in other professions mistakenly regarded as more honourable. 